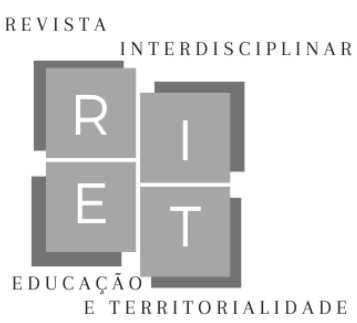

\title{
I can't breathe: reflexões sobre colonialidade e Covid-19 a partir da cidade de Nova Iorque, $\mathbf{E U A}^{1}$
}

\author{
I can't breathe: reflections about coloniality COVID-19 since New York City, \\ USA
}

I can't breathe: reflexiones sobre colonialidad y Covid-19 de la ciudad de Nueva York, EE. UU.

Soraya Franzoni Conde Programa de Pós-graduação em Educação, Programa de Pós-graduação em Serviço Social, Universidade Federal de Santa Catarina (UFSC) Professora visitante na City University of New York (CAPES/PRINT) New York City, New York, Estados Unidos da América E-mail: sorayafconde@gmail.com ORCID: http://orcid.org/0000-0002-5271-6479

Suzani Cassiani ${ }^{2}$ Programa de Pós-graduação em Educação Científica e Tecnológica, Universidade Federal de Santa Catarina (UFSC)

Florianópolis, Santa Catarina, Brasil.

E-mail: suzanicassiani@gmail.com ORCID: https://orcid.org/0000-0001-8824-9342

Resumo: O objetivo deste texto é refletir sobre como a Covid-19 se manifesta na cidade de Nova Iorque, considerada o epicentro da pandemia nos Estados Unidos da América, durante o primeiro semestre de 2020. Ele é produto de coleta diária de dados e informações realizada durante os meses de março e junho de 2020 em meios de comunicação estadunidenses e brasileiros, em relatórios disponibilizados pela Prefeitura de Nova Iorque, além de leituras, discussões e análises coletivas feitas a partir do referencial teórico crítico, com os grupos de estudos e pesquisas dos quais as autoras participam. A coleta de dados foi realizada buscando perceber quem são as principais vítimas da Covid-19 e qual o contexto em que estavam inseridas. Para isso, primeiramente, contextualizamos a cidade de Nova Iorque, destacando suas características sociais gerais, dadas pela organização espacial territorial desigual. Em seguida, analisamos os dados nos quais aparece o que denominamos de colonialidade, onde latinos, negros e mulheres constituem os grupos sociais mais fragilizados e atingidos pela

\footnotetext{
${ }^{1}$ Este artigo é parte das pesquisas desenvolvidas no âmbito do projeto "Repositório de Práticas Interculturais: Proposições para Pedagogias Decoloniais", desenvolvido junto ao Programa de Internacionalização CAPES/PRINT/UFSC. Parte da coleta dos dados foi feita durante o estágio da primeira autora deste artigo, professora visitante na City University of New York, com bolsa CAPES/PRINT/UFSC. O projeto de pesquisa da primeira autora recebe apoio financeiro da Fundação de Amparo à Pesquisa e Inovação do Estado de Santa Catarina (Fapesc), Edital 06/2016.

${ }^{2}$ Bolsista Produtividade CNPq $-1 \mathrm{C}$.
} 


\section{I can't breathe: reflexões sobre colonialidade e Covid-19 a partir da cidade de Nova Iorque, EUA}

pandemia no Norte Global, revelando a existência do Sul colonizado e explorado dentro do Norte explorador e colonizador. Por meio de uma perspectiva educacional ativista, crítica, transformadora e anticolonialista/anticapitalista, este artigo contribui para relevar e superar essa realidade, problematizando as desigualdades e oferecendo ferramentas críticas para um reposicionamento ativista transformador dos(as) oprimidos(as).

Palavras chaves: Pandemia. Educação. Colonialidade.

Abstract: The purpose of this text is to reflect on how COVID-19 manifests itself, mainly, in New York City (United States) from the relationship between the categories class, race and gender and the contribution of education in a critical perspective. It is the product of daily data and information collection carried out during the months of March and June 2020 in American and Brazilian media, in reports made available by the New York City Hall, in addition to readings, discussions and collective analyzes, based on the framework critical theoretical, carried out in groups of studies and research. For that, first, we contextualize the city of New York highlighting general social characteristics given by the unequal territorial spatial organization. Then, we reflect on the effects of the pandemic in relation to social class, race and sex / gender. Finally, we consider that class, race and gender constitute different parts of the same totality where a privileged minority exploits the majority that appears in an opposite, fragmented, divided way. It is the role of critical and transformative education to contribute to overcoming this reality, because if education does not change the world, it is an important aspect of human formation where our intentions are able to boost our actions.

Keywords: Pandemic. Education. Coloniality

Resumen: El propósito de este texto es reflexionar sobre cómo se manifiesta la Covid-19 en la ciudad de Nueva York, considerada el epicentro de la pandemia en los Estados Unidos de América durante el primer semestre de 2020. Él es producto de la recolección diaria de datos e información realizada durante los meses de marzo y junio de 2020 en medios de comunicación estadounidenses y brasileños, en informes proporcionados por el Ayuntamiento de Nueva York, además de lecturas, discusiones y análisis colectivos, basados en el marco teórico crítico, realizados en grupos de estudios e investigaciones de los cuales participan los autores. La recolección de datos se realizó con el fin de comprender quiénes son las principales víctimas de la Covid-19 y cuál es su contexto. Para ello, en primer lugar, contextualizamos la ciudad de Nueva York, destacando las características sociales generales dadas por la desigual organización espacial territorial. Luego, analizamos los datos recolectados en los que aparece la (neo) colonialidad, ya siendo latinos, negros y mujeres los grupos sociales más vulnerables y afectados por la pandemia en el Norte Global, lo que muestra la existencia del Sur colonizado y explotado dentro del Norte explorador y colonizador. A través de una perspectiva educativa activista, crítica, transformadora, anticolonialista/anticapitalista, este artículo contribuye para resaltar y superar esta realidad, problematizando las desigualdades y ofreciendo herramientas críticas para un reposicionamiento activista transformador de los oprimidos.

Palabras clave: Pandemia. Educación. Colonialidad.

Data de recebimento: 20/01/2021

Data de aprovação: 10/06/2021

DOI: $10.30612 /$ riet.v\%vi\%i.13404

\section{Introdução}

RIET-ISSN 2676-0355, Dourados, v. 2, n. 2, p. 286 a 303, jan./jun., 2021 


\section{I can't breathe: reflexões sobre colonialidade e Covid-19 a partir da cidade de Nova}

Iorque, EUA

\begin{abstract}
Não consigo respirar
Disse George Floyd

Com o joelho de quatrocentos anos de racismo

No seu pescoço

Não consigo respirar

Disse Pedro Gonzaga,

Um rapaz de 19 anos

Asfixiado pelo peso do segurança

do supermercado Extra

Negro como ele

Não consigo respirar

Disse a mulher,

Com olhar de medo,

Seus pulmões destroçados pelo coronavírus

Antes de ser entubada

Não consigo respirar

Disse a enfermeira, exausta

Depois de um longo turno de trabalho

Suando sob sua máscara

E com a vista embaçada [...]
\end{abstract}

(Dzung Vo, poeta vietnamita que vive no Canadá)

I can't breathe! Iniciamos este texto com a frase que tomou as ruas de Nova Iorque e de outras cidades do mundo durante os protestos contra o racismo motivados pelo assassinato do segurança George Floyd por policiais de Mineápolis, EUA, no dia 25 de maio de 2020. Dramáticas, as últimas palavras de Floyd coincidem com o estado de quem morre por Síndrome Respiratória Grave, desencadeada pelo novo coronavírus, que acomete e vitimiza milhares de pessoas, impossibilitadas de respirar. Nesse sentido, há um fio contínuo de opressões, explorações e colonialidade ligando o assassinato de Floyd à morte de milhares de negros, negras, latinos, latinas e demais imigrantes vítimas do novo coronavírus nos Estados Unidos, na América Latina e no mundo. Segundo a Organização Mundial de Saúde (OMS) (WHO, 2020), até o dia 5 de junho de 2020, o Planeta Terra teve 371.166 mortes confirmadas pela Covid-19, entre as quais 108 mil nos EUA e 30 mil no Brasil.

Em vista disso, o objetivo deste texto, para além de desvelar e refletir sobre 'What's going on?', ou 'O que está acontecendo?', é debater sobre a forma desigual com que a pandemia se manifesta e sobre a existência da colonialidade, ou do que chamamos de Sul no Norte Global. Também, por meio dele, reafirmar o engajamento das autoras - professoras, pesquisadoras e brancas - na luta antirracista, antimachista e antixenofobia, com vistas a um posicionamento ativista transformador (STETSENKO, 2017) contra toda e qualquer forma de opressão e injustiça sociais. Concordamos com Taylor (2018) a respeito do fato de que a

RIET-ISSN 2676-0355, Dourados, v. 2, n. 2, p. 286 a 303, jan./jun., 2021 


\section{I can't breathe: reflexões sobre colonialidade e Covid-19 a partir da cidade de Nova Iorque, EUA}

luta pela superação do racismo se dá de forma conjunta e solidária entre negros(as), imigrantes, latinos(as), indígenas, homossexuais, transexuais, trabalhadores e trabalhadoras brancos(as), pobres e explorados(as).

Em termos metodológicos, procedeu-se à coleta diária de dados e informações durante os meses de março e junho de 2020, em meios de comunicação estadunidenses e brasileiros, em especial nos relatórios oficiais disponibilizados pela Prefeitura de Nova Iorque. Os dados foram analisados à luz de discussões coletivas, a partir do referencial teórico crítico, com os pesquisadores dos seguintes grupos de estudos: a Peer Activist Learning Community (Palc), da City University of New York, o Grupo de Estudos Trabalho, Educação e Infância (Getei) e o Grupo de Estudos Discursos da Ciência e da Tecnologia na Educação (Digite), ambos da Universidade Federal de Santa Catarina (UFSC).

O texto está estruturado da seguinte forma: primeiramente, destacamos o contexto da cidade de Nova Iorque, caracterizada pela organização territorial segregada e pela síntese de diferentes opressões e explorações. Em seguida, a partir dos dados coletados, refletimos sobre a existência do Sul no Norte Global a partir de reflexões sobre classe social, raça/etnia e gênero/sexo. Por último, destacamos que a crise da Covid-19 é fruto das desigualdades sociais geradas pelo sistema capitalista (MARX, 2013), caracterizado pelo colonialidade (QUIJANO, 2019) e pela necropolítica (MBEMBE, 2018), decorrentes do avanço do neoliberalismo, que aprofunda a exploração no trabalho, assim como o racismo, a pobreza, a violência de gênero e outras opressões, sobretudo em grupos sociais historicamente explorados e colonizados.

Esse colonialismo, manifesto nas formas de contratação terceirizadas, precarizadas e uberizadas, nas quais trabalhadores(as) considerados(as) essenciais não desfrutam do direito à quarentena nem mesmo no Norte Global, é um dos problemas a serem enfrentados pela esfera educacional, entendida de forma ampla, e não restrita à escola. Se a educação não é a panaceia social, conforme sentencia Meszáros (2008), também é certo que nenhuma sociedade sobrevive sem uma educação baseada em valores correspondentes aos seus interesses. Nesse sentido, uma educação crítica, transformadora, posicionada, anticapitalista e decolonialista pode contribuir para a superação dessa realidade, problematizando essas desigualdades e favorecendo o posicionamento ativista transformador por parte de grupos historicamente oprimidos (STESENKO, 2017; FREIRE, 2019). 


\section{I can't breathe: reflexões sobre colonialidade e Covid-19 a partir da cidade de Nova Iorque, EUA}

\section{O contexto do "epicentro" da pandemia}

Símbolo da ideologia da liberdade individual como expressão de um modo de vida considerado rico e libertário no Norte Global, a densa cidade de Nova Iorque vive dias catastróficos durante a crise causada pela Covid-19, com ruas vazias, lojas, restaurantes e comércios fechados, além do barulho constante e ensurdecedor de ambulâncias que percorrem diuturnamente as ruas. Estima-se que cerca de 2,7 mil pequenos comércios faliram e que $87 \%$ dos estabelecimentos restantes não possuem condições de pagar seus aluguéis. O índice de desemprego ultrapassa $30 \%$, e há um movimento de 'fuga' da população branca, rica e privilegiada para casas de campo e de praia localizadas em pequenas cidades distantes dos grandes centros urbanos norte-americanos. Especuladores estimam uma forte crise imobiliária, com possibilidade de tonar Nova Iorque uma cidade fantasma, tal qual a falência da indústria automobilística fizera com Detroit há poucos anos. Com o fechamento dos comércios e o esvaziamento das ruas, ganham destaques os invisíveis: milhares de moradores(as) de ruas, a maioria negros(as), pedindo comida e dinheiro.

Com quase a metade da população do Estado, a cidade é composta pelos bairros Brooklyn, Queens, Manhattan, The Bronx e Staten Island, conforme ilustrado na Tabela 1, abaixo:

Tabela 1 - População dos bairros de Nova Iorque, EUA - 2018

\begin{tabular}{|c|c|c|c|c|c|}
\hline \multicolumn{6}{|c|}{ Bairros da Cidade de Nova Iorque } \\
\hline Bairro & $\begin{array}{c}\text { População } \\
\text { Estimada } \\
\text { (2018) }\end{array}$ & $\begin{array}{c}\text { Renda } \\
\text { bilhões } \\
\text { (US\$) }\end{array}$ & $\begin{array}{c}\text { Renda } \\
\text { per capita } \\
\text { (US\$) }\end{array}$ & $\begin{array}{l}\text { Área } \\
\left(\mathbf{k m}^{2}\right)\end{array}$ & Pessoas $/ \mathbf{k m}^{2}$ \\
\hline The Bronx & $1.432,132$ & 42.695 & 29,200 & 109.04 & 13,231 \\
\hline Brooklyn & $2.582,830$ & 91.559 & 34,600 & 183.42 & 14,649 \\
\hline Manhattan & $1.628,701$ & 600.244 & 360,900 & 59.13 & 27,826 \\
\hline Queens & $2.278,906$ & 93.310 & 39,600 & 281.09 & 8,354 \\
\hline Staten Island & 476,179 & 14.514 & 30,300 & 151.18 & 3,132 \\
\hline $\begin{array}{c}\text { Cidade de } \\
\text { Nova Iorque }\end{array}$ & $8.398,748$ & 842.343 & 97,700 & 783.83 & 10,947 \\
\hline
\end{tabular}




\section{I can't breathe: reflexões sobre colonialidade e Covid-19 a partir da cidade de Nova Iorque, EUA}

\begin{tabular}{llllll} 
Estado de Nova & $19.745,289$ & 1.701 .399 & 85,700 & 122,284 & 159 \\
Iorque & & & & & \\
\hline
\end{tabular}

Fonte: New York (2020).

Segundo a Tabela 1, o bairro de Manhattan possui a maior densidade populacional da cidade. Presos à aparência, poderíamos olhar para os números gerais de atingidos pela Covid-19 e explicá-los pela densidade populacional. Mas, como diria Marx (2013), os dados gerais de uma população são apenas a aparência de um fenômeno. É preciso ciência para compreender como os discursos veiculados na sociedade podem distorcer nossa compreensão da realidade. Nesse sentido, vejamos os dados a seguir (Figura 1) sobre a contaminação da Covid-19 em cada bairro de Nova Iorque:

Figura 3: Número de casos por bairro em Nova Iorque.

\begin{tabular}{|c|c|c|c|}
\hline & r & Rate per 100,000 people & Count \\
\hline The Bronx & & 1,835 & 27,014 \\
\hline Staten Island & & 1,830 & 9,166 \\
\hline Queens & & 1,494 & 37,447 \\
\hline Brooklyn & & 1,197 & 32,499 \\
\hline Manhattan & 845 & & 15,952 \\
\hline Citywide & & & 122,148 \\
\hline
\end{tabular}

Fonte: https://www1.nyc.gov/site/doh/covid/covid-19-data.page. Acesso em 17 de abril de 2020.

De acordo com os dados da Figura 1, o maior índice absoluto de contaminação se encontra no Queens, seguido por Brooklyn, The Bronx, Manhattan e Staten Island. Como podemos observar, contrariando afirmações superficiais sobre densidade populacional, não é de Manhattan (bairro mais denso e mais rico de Nova Iorque, cuja renda média é dez vezes maior do que a do segundo bairro mais rico) o maior índice de contaminados pela Covid-19, e sim do Queens, onde residem milhares de imigrantes latino-americanos(as), muitos(as) em situação ilegal/indocumentada, que constituem a força de trabalho mais barata e sujeita ao subemprego. Em seguida, aparece o Brooklyn, bairro também caracterizado pela forte diversidade cultural, pela mistura étnica entre migrantes de diferentes locais do mundo e pelo alto índice de afro-americanos(as) e latinos(as). Em terceiro lugar, figura a região do

RIET-ISSN 2676-0355, Dourados, v. 2, n. 2, p. 286 a 303, jan./jun., 2021 


\section{I can't breathe: reflexões sobre colonialidade e Covid-19 a partir da cidade de Nova Iorque, EUA}

The Bronx, tradicionalmente conhecida pela maior concentração de negros(as) americanos(as) da cidade, seguida da de imigrantes latinos(as).

O cruzamento dos dados da Tabela 1 com os da Figura 1 nos leva a questionar a relação entre pandemia, raça e classe social. Embora o discurso veiculado inicialmente pelas mídias e pelos políticos de várias partes do mundo afirme que 'pandemias e vírus não escolhem classe social', a concentração do número de atingidos nos bairros de imigrantes trabalhadores(as) e de negros(as) evidencia que os recursos para a proteção contra o contágio e a recuperação econômica são apropriados de forma desigual e condicionados pelas condições de vida, que servem de critério para a decisão sobre quem deve morrer ou viver.

Nesse mesmo sentido, destacamos os pacotes trilionários de ajuda destinados aos bancos e aos grandes empresários, no Brasil, nos EUA e no mundo. Em contraponto, aos(às) pobres, negros(as), imigrantes, trabalhadores(as) e deficientes, residentes nas localidades mais desvalorizadas, além de migalhas que não atingem o mínimo necessário, restam inúmeros obstáculos ao acesso, como a burocracia e as filas, locais onde o risco de contaminação é ainda mais elevado.

Segundo Taylor (2018), o capitalismo é um sistema baseado na exploração de muitos por poucos privilegiados. Sua base está assentada sobre uma forte desigualdade social, que se utiliza de ferramentas requintadas para dividir a maioria explorada. Com base no mito da escassez e usando do racismo e do colonialismo para espoliar, explorar, dominar e escravizar, cria uma competição entre os explorados, colocando-os uns contra os outros. Divididos pela cor da pele, pela origem, pela religião ou pelo sexo, deixam de lado a luta unificada da maioria contra a minoria. O sentimento de privilégio (real e verdadeiro) confunde os brancos, que passam a não se identificar com as pautas dos não brancos. $\mathrm{O}$ inverso também ocorre, e não brancos também não se identificam com as pautas dos brancos explorados e membros da classe trabalhadora. As formas confundem e criam uma falsa aparência, que, no fundo, diante da fragmentação dos explorados, beneficia apenas os exploradores.

Essa ideologia da supremacia branca tem surtido efeitos sobre os EUA, fato observável nos dados sobre violência, pobreza e qualidade de vida. Nesse sentido, Taylor (2018) mostra como, nos lugares em que a ideia da supremacia branca prosperou, o movimento trabalhista declinou e instituiu-se uma verdadeira guerra entre brancos e não brancos. Ainda segundo a autora, a forma como a teoria racial e a ideologia da supremacia 


\section{I can't breathe: reflexões sobre colonialidade e Covid-19 a partir da cidade de Nova Iorque, EUA}

branca foram implementadas nos EUA (sob fortes financiamentos da Fundação Ford) culminou na disseminação de uma abordagem superficial do problema racial, tomada pelo sentimento de ódio e pela competição entre brancos e negros.

Tanto nos Estados Unidos quanto no Brasil (vice-campeão mundial em desigualdade social), é lugar-comum o desenvolvimento da necropolítica (MBEMBE, 2018), caracterizada pelo genocídio de jovens negros(as) e pobres da periferia, em grande parte exterminados(as) pela violência policial. Conforme Gonzalez (2018) e Nascimento (1978), quanto mais pobre é a população, maior porcentagem de negros(as) ela tem. Ou seja, categorias como raça e classe se entrecruzam e evidenciam que o fato de ser negro(a) ou imigrante não pode ser entendido fora do contexto e das relações sociais em que se vive, tanto no Sul quanto no Norte Global, compondo a manifestação contemporânea de colonialidade ou (neo)colonialismo. Conforme Quijano (2019, p. 151):

La colonialidade es uno de los elementos constitutivos y específicos del patrón mundial de poder capitalista. Se funda en la imposición de una clasificación racial/étnica de la población del mundo como piedra angular de dicho patrón de poder y opera en cada uno de los planos, ámbitos y dimensiones materiales y subjetivas, de la existencia cotidiana y a escala social. Se origina y se mundializa a partir da América.

Se, no passado, o sistema colonial tinha na escravidão de negros(as) e índios(as), no roubo de recursos naturais das colônias, no genocídio, no estupro e na violência contra mulheres e povos originários o elemento central da acumulação primitiva capitalista (MARX, 2013), hoje as grandes metrópoles foram substituídas por grandes transnacionais, sediadas em países do Norte Global, cuja principal forma de valorização se dá nos mercado de ações e na exploração dos recursos naturais, da força de trabalho e das commodities nos países do Sul, a exemplo do que acontece na América Latina e na África. Com o crescimento do fluxo migratório internacional, sobretudo da população desempregada de países em crise ou em guerra, também se cria no interior dos países ricos do Norte Global um muro que divide o Norte, da elite branca supremacista, e o Sul, de latinos(as) e negros(as) explorado(as) e sem direitos garantidos, vítimas do novo Coronavírus e daquilo que Mbembe (2018) chama de necropolítica.

Para Mbembe (2018), a necropolítica se caracteriza pelo poder de ditar quem pode viver e quem deve morrer. É executada por meio de sofisticadas tecnologias, usadas para controlar as populações pobres, consideradas uma ameaça social. Assim, 'deixa-se' que

RIET- ISSN 2676-0355, Dourados, v. 2, n. 2, p. 286 a 303, jan./jun., 2021 


\section{I can't breathe: reflexões sobre colonialidade e Covid-19 a partir da cidade de Nova Iorque, EUA}

alguns morram e protegem-se os outros. O corpo 'matável' é geralmente definido pelo critério da raça; logo, os não brancos são mais 'matáveis' do que os brancos, independentemente da classe. $O$ autor explica que o uso desse termo tem a função pedagógica de demonstrar, no mundo contemporâneo, as mais diversas formas com que se revestem as estruturas criadas para matar, controlar e destruir vidas. Ou seja, certas vidas valem mais do que outras, e aquelas que podem ameaçar a manutenção do status quo e da propriedade privada capitalista devem ser controladas.

Se, por um lado, toda sociedade necessita de normas gerais para regular a vida social, por outro, a atual forma social cria espaços de morte, transformados na principal forma de controle e dominação. Mbembe (2018) afirma que quem morre em espaços como estes são grupos geralmente selecionados pelo critério biológico e com base no racismo. O mecanismo é sempre o mesmo: determinado grupo aparece como inimigo nos discursos gerais midiáticos, políticos e fictícios -; em seguida, seu extermínio aparece como solução para o que a burguesia intitula de paz. Assim, a violência é justificada como um 'mal necessário', ou melhor, como mecanismo de segurança e de manutenção da paz burguesa e do direito à propriedade privada. $\mathrm{O}$ mesmo poderia ser dito do controle policial e militar existente nas fronteiras dos EUA com México, da guerra norte-americana contra o Islã e da violência policial nas favelas e periferias do Brasil e do mundo, onde predominam populações não brancas.

Voltando aos dados sobre a cidade de Nova Iorque, observamos que é exatamente nos bairros em que os(as) trabalhadores(as) migrantes de origem latina e negra residem que se encontram os maiores índices de concentração da Covid-19, evidenciando que a ocupação do espaço e do território não é neutra, mas sim a expressão das forças sociais em disputa (VENDRAMINI; CONDE, 2020). Segundo Milton Santos (1993, p. 81), o valor de cada pessoa depende do lugar em que ela está, pois “[...] o seu valor como produtor, consumidor, cidadão, depende de sua localização no território".

\section{O Sul no Norte Global: manifestações da Covid-19 em relação à raça, ao sexo/gênero e à classe}

Produto da segregação social e racial monstruosa e intrínseca à história dos EUA, a população negra nova-iorquina, seguida pelos imigrantes latino-americanos, compõe o grupo social mais severamente atingido pela Covid-19:

RIET-ISSN 2676-0355, Dourados, v. 2, n. 2, p. 286 a 303, jan./jun., 2021 


\section{I can't breathe: reflexões sobre colonialidade e Covid-19 a partir da cidade de Nova Iorque, EUA}

Figura 4: Contaminados, curados e mortos pelo COVID-19 por origem racial

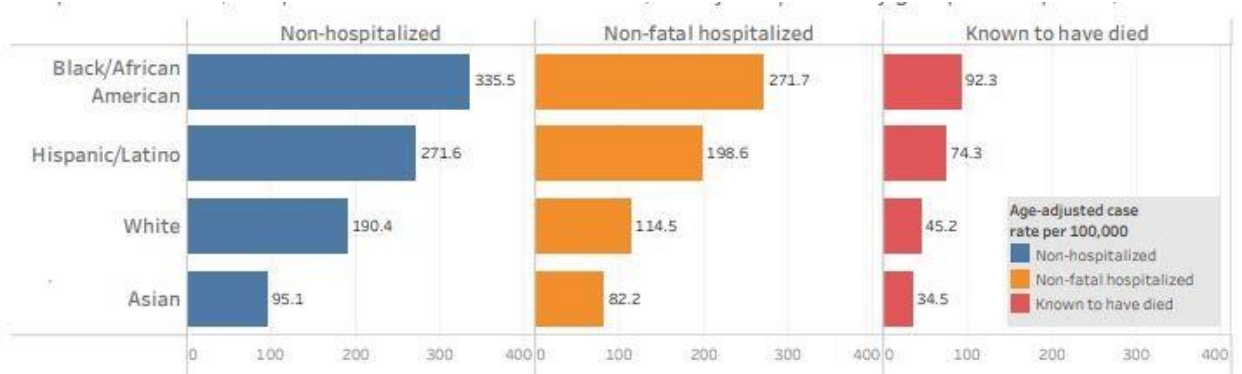

Fonte: https://www1.nyc.gov/assets/doh/downloads/pdf/imm/covid-19-deaths-raceethnicity-04162020-1.pdf. Acesso em 20 de abril de 2020

Observamos que, nas três categorias sistematizadas (doentes não hospitalizados; doentes hospitalizados e curados; e mortos registrados), os(as) negros(as) americanos(as) e os(as) imigrantes latinos(as) são os maiores grupos de atingidos, seguidos(as) dos(as) brancos(as) americanos(as) e dos(as) asiáticos(as). A relação entre doentes não hospitalizados, curados e mortos é o dobro entre negros(as) americanos(as) e imigrantes latinos(as) do que entre brancos(as) e imigrantes asiáticos(as).

Conforme Wilhians (2020), os dados da Covid-19 expressam o racismo e a exploração estrutural e institucional presentes em três aspectos: 1) no número de contaminados, em virtude de a população negra (e latina) ter menos condições de realizar quarentena, por viver nas piores condições de trabalho, renda e moradia; 2) no número dos que conseguem atendimento e tratamento: num país sem sistema público universal de saúde (paraíso dos planos privados, com altíssimo índice de endividamento pessoal por tratamentos de saúde), negros(as) e imigrantes são impedidos(as) de acessar os serviços de tratamento; 3) no número de curados e de mortos: após acessarem o serviço dos hospitais, ocorre uma segregação, oriunda do fato de os(as) médicos(as) e enfermeiros(as) serem formados(as) para atender brancos(as) e ricos(as), critério que pesa na hora de escolherem quem deverá ser tratado primeiro. Também são comuns os casos de médicos(as) que entendem que os(as) negros(as) possuem mais resistência à dor do que os(as) brancos(as) e, por isso, utilizam dozes menores de anestésicos durante procedimentos cirúrgicos ou tratamentos.

$\mathrm{O}$ autor e ativista ainda destaca que os dados sobre os contaminados devem ser interpretados cuidadosamente, pois o problema racial é errônea e comumente atribuído pela supremacia branca à origem biológica e hereditária - ou seja, há uma nova eugenia operante 


\section{I can't breathe: reflexões sobre colonialidade e Covid-19 a partir da cidade de Nova Iorque, EUA}

-, quando, na realidade, ele é produto de uma estrutura social desigual, racista e xenófoba, que condena pobres, negros(as) e latinos(as) às piores condições de vida e de acesso à saúde, alimentação, moradia e direitos (WILHIANS, 2020).

Os discursos de eugenia, que lamentavelmente ainda se fazem presentes na vida política e na ciência, em razão do avanço da crise capitalista e do pensamento conservador da elite branca no Norte Global, mostram uma ideia de supremacia branca originalmente veiculada pelos colonizadores que escravizaram os nativos na América, na África e na Ásia. Nos territórios invadidos, alimentaram uma subjetividade que alude à ideia de que o homem branco e europeu é superior aos outros humanos. Essa noção de colonialidade e racismo, ainda presente nos dias atuais, tem um efeito devastador, que subalterniza, inferioriza e mata quem não se enquadra no padrão ocidental higienista (CASTRO-GÓMEZ; GROSFOGEL, 2007) e justifica a exploração e a expropriação dos não brancos. Nesse caminho, a maior parte das pessoas negras e dos(as) imigrantes (latinos/as, no caso dos EUA) está submetida às piores condições de vida e de trabalho, inclusive no Norte Global, como evidenciado pelos dados da cidade de Nova York. Assim, não brancos(as) são impossibilitados(as) de manter o distanciamento social, de ficar em casa e de ter acesso à boa alimentação e aos produtos de sanitização. Nos EUA, assim como no Brasil, as maiores taxas de hipertensão, diabetes e doenças cardíacas também se encontram entre a população negra, todas elas relacionadas às condições de vida, especialmente à falta de acesso à alimentação saudável e aos serviços de saúde (GASPER, 2020).

O problema ganha proporções ainda maiores quando percebemos que os EUA são o país com o maior índice de imigrantes do mundo (sobretudo de países asiáticos e latinos), a maioria dos quais permanece trabalhando ilegalmente e é submetida às piores condições de trabalho, compondo uma parcela disposta a aceitar, por necessidade, os trabalhos mais vis e os piores salários. Assim, a quarentena, além de ser possível apenas para uma pequena parcela da população, requer certas condições de infraestrutura, como, por exemplo, a manutenção das prateleiras dos supermercados cheias, para que todos os que possuam condições de comprar consigam se manter em casa e bem alimentados. Mas quem produz esses alimentos e materiais? No interior dos EUA, cerca de $80 \%$ da produção agrícola têm como base a exploração de milhares de imigrantes latino-americanos(as) ilegais e sazonais, considerados(as) trabalhadores essenciais durante a pandemia, não obstante sejam os(as) principais atingidos(as) pela Covid-19 no interior do país. Mas como poderia um trabalho

RIET-ISSN 2676-0355, Dourados, v. 2, n. 2, p. 286 a 303, jan./jun., 2021 


\section{I can't breathe: reflexões sobre colonialidade e Covid-19 a partir da cidade de Nova Iorque, EUA}

essencial ser realizado por um(a) migrante ilegal? Essa contradição, insolúvel pela base de exploração do trabalho capitalista, foi revelada pelo New York Times (JORDAN, 2020) em reportagens que mostraram fazendeiros americanos reclamando de que as deportações de imigrantes de 2017 elevaram os salários dos trabalhadores rurais e diminuíram as taxas de lucro (VENDRAMINI; CONDE, 2020).

Durante a crise da Covid-19, as questões que envolvem sexo/gênero, entendidas para além da determinação biológica e feminina, também merecem uma atenção especial, que suplante a aparência. Os dados oficiais divulgados pela Prefeitura de Nova Iorque evidenciam que o número de mulheres contaminadas é menor do que o de homens:

Figura 6: Número de contaminados/as por sexo na Cidade de Nova Iorque

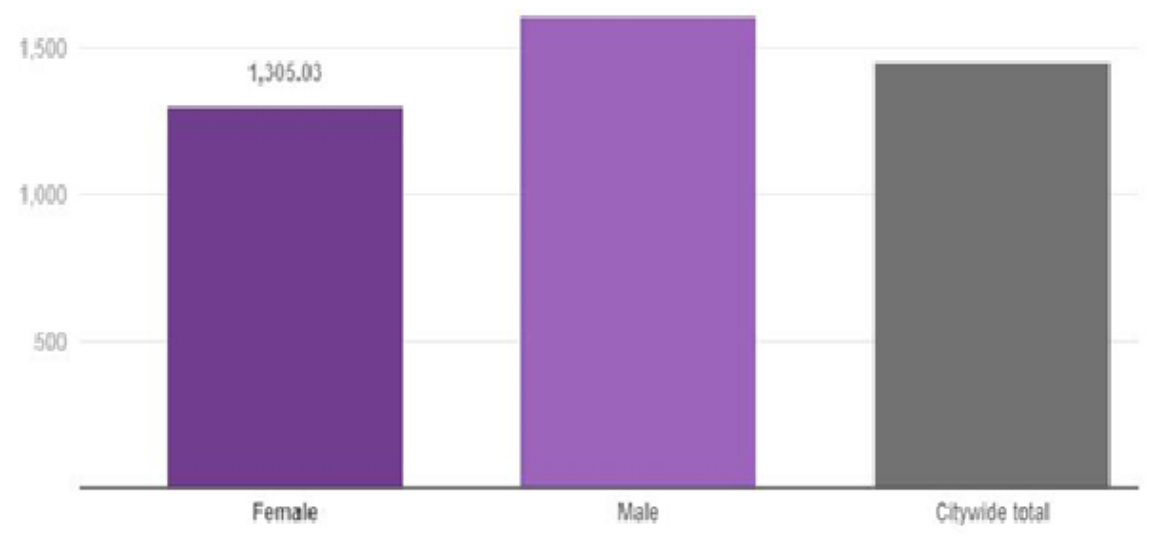

Fonte: https://www1.nyc.gov/site/doh/covid/covid-19-data.page. Acesso em 20 de abril de 2020.

Não fossem os elementos históricos que envolvem o trabalho feminino e reprodutivo, os dados poderiam evidenciar um favorecimento inato do sexo feminino entre as pessoas contaminadas. Entretanto, a história mostra que, desde os primórdios da acumulação primitiva de capital, as mulheres foram impedidas de acessar o trabalho remunerado e permaneceram mais restritas ao trabalho privado, doméstico e de cuidados, partes essenciais da reprodução familiar e do futuro do trabalho explorado na sociedade capitalista (FEDERICI, 2014).

Impossibilitadas de acessar o trabalho assalariado, fato intensificado pelos cercamentos da acumulação primitiva e pelo desenvolvimento do trabalho industrial, a concentração da pobreza se tornou maior entre as mulheres. Embora quase a metade da força de trabalho remunerada no mundo, hoje, seja formada por mulheres, elas ficam com pouco

RIET-ISSN 2676-0355, Dourados, v. 2, n. 2, p. 286 a 303, jan./jun., 2021 


\section{I can't breathe: reflexões sobre colonialidade e Covid-19 a partir da cidade de Nova Iorque, EUA}

mais de $10 \%$ da riqueza produzida mundialmente. Quando entram no mercado de trabalho, além de assédio e violências constantes, recebem salários mais baixos e exercem cargos de menor prestígio e poder de decisão (HIRATTA, 1993). Quando há divisão de tarefas domésticas, as mulheres permanecem desempenhando o trabalho privado de reprodução e cuidados (cozinhar, passar, lavar, atender, educar e dar afeto), enquanto os homens costumam assumir as compras, pagar contas, entre outras atividades que implicam sair de casa e circular socialmente (CONDE, 2018).

Nesse sentido, embora o gênero não possa ser pensado sem referência ao sexo, ele vai além da esfera biológica, uma vez que a cultura é o que conforma o padrão do que entendemos por mulheres ou homens. $\mathrm{O}$ mesmo raciocínio pode ser estendido à raça e à classe. Ambas não podem ser unicamente definidas pelas esferas econômica ou biológica, mas sim pela identidade e a subjetividade daqueles que vivem a condição de sua classe e de sua raça (SAFFIOTTI, 2013; SHIELDS, 2020).

A pandemia ocasionada pelo novo Coronavírus tem mobilizado um gigantesco trabalho nas áreas dos cuidados e da saúde. Conforme relatório recém-publicado pela ONU Mulheres Brasil (MLAMBO-NGCUKA, 2020), cerca de 70\% da força de trabalho do setor de saúde é composta por mulheres, proporção que alcança $85 \%$ na enfermagem. Ou seja, o trabalho de cuidados, majoritariamente desempenhado por mulheres, está sendo fortemente impactado pela pandemia. Expostas ao risco constante de contaminação, têm se tornado comuns as paralisações e mobilizações em prol de equipamentos de proteção de qualidade e em número suficiente.

Como o trabalho de cuidados é social e economicamente desvalorizado, cuidadoras e enfermeiras frequentemente acumulam vários empregos. Tanto nos EUA como em outras partes do mundo, as mulheres pobres, negras e latinas constituem a principal força de trabalho em atividades que requerem cuidados, pelas quais perpassam claramente o racismo e o colonialismo, que destinam a certos grupos femininos posições de menor prestígio e remuneração.

Também a desvalorização do trabalho de cuidados é reflexo da desvalorização histórica da esfera da reprodução no sistema capitalista, na qual o trabalho produtivo, majoritariamente desempenhado por homens fora da esfera doméstica, recebe maior prestígio e valorização monetária. Essa lógica despreza a inexistência real da dicotomia entre 


\section{I can't breathe: reflexões sobre colonialidade e Covid-19 a partir da cidade de Nova Iorque, EUA}

natureza e cultura, objetividade e subjetividade, produção e reprodução e se manifesta nas compreensões binárias e equivocadas sobre classe e sexo/gênero ou classe e raça.

Além disso, o aumento do isolamento, dos cuidados e dos contaminados impacta a vida feminina, constantemente dividida entre duplas/triplas/quádruplas jornadas de trabalho. Os cuidados são agora redobrados entre os idosos da família (mais vulneráveis) e os filhos (sem escola nem espaços de socialização fora de casa). Quando os homens em idade produtiva de trabalho adoecem, são geralmente cuidados pelas mulheres, sejam elas companheiras, amigas, irmãs, mães, filhas, avós ou esposas. Nesses trabalhos, constituem o front de batalha, portanto estão mais expostas e sobrecarregadas com a pandemia. Em todos os casos, as mulheres pobres e trabalhadoras, por não terem condições de pagar pelo serviço de outras cuidadoras nem por outros serviços essenciais, são mais afetadas e sobrecarregadas, sejam elas negras, latinas ou brancas.

Conforme Federici (2014), a questão do cuidado, que sobrecarrega mulheres (sobretudo negras, latinas e pobres) desde o período colonialista da acumulação primitiva do capital, intensifica-se em momentos de crise (como a pandemia) e evidencia a importância da esfera da reprodução na família e na sociedade. Nesse sentido, os cuidados que as mulheres desempenham dentro de casa, nos hospitais e escolas são fundamentais para o futuro do trabalho na sociedade capitalista. A histórica desvalorização dessa esfera é reflexo de uma supervalorização do que gera lucro imediato, expressa em movimentos conservadores pela abertura de comércios e instituições fechadas durante a quarentena.

Como se não bastassem tais dados, permanecer em casa não significa estar segura. No mundo todo, o isolamento social tem culminado no aumento da violência doméstica: $30 \%$ na França, $18 \%$ na Espanha, 30\% em Singapura, 50\% no Brasil e 35\% nos EUA (BORGES; LARA, 2020). Esse fato pode ser explicado pelo confinamento com companheiros violentos e altamente tensionados pela crise financeira e pela impossibilidade de prover o sustento familiar numa sociedade em que valores patriarcais e tradicionais cobram dos homens a responsabilidade principal pelo sustento da casa. A maior parte das violências ocorre na frente das crianças, em virtude das escolas estarem fechadas. As casas de acolhimento de mulheres em situação de violência também não estão aceitando novas moradoras por conta do risco de contaminação. Mais uma vez, é a mulher pobre e trabalhadora, negra e imigrante quem sofre os maiores efeitos da pandemia, o que evidencia como a realidade da crise gerada pela Covid-19 articula de forma muito evidente a relação

RIET-ISSN 2676-0355, Dourados, v. 2, n. 2, p. 286 a 303, jan./jun., 2021 


\section{I can't breathe: reflexões sobre colonialidade e Covid-19 a partir da cidade de Nova Iorque, EUA}

entre sexo/gênero, classe e raça como um todo estruturado, articulado e inseparável, expressão da forma combinada entre capitalismo avançado e colonialidade.

\section{Considerações finais: a contribuição da educação para um posicionamento ativista transformador dos oprimidos contra o opressor}

O/a leitor/a ingênuo/a poderá questionar sobre qual a relação da educação com os elementos, dados e reflexões destacadas no texto. Entendemos que se é papel da ciência ultrapassar a aparência, também é desvelar os véus ideológicos presentes em meios de comunicação de massa e em teorias burguesas racistas e xenófobas. Entender porque negros e latinos se contaminam e morrem mais de COVID-19 no interior de uma sociedade fundada na desigualdade social, no racismo e na exploração é fundamental para romper com discursos higienistas que explicam os problemas sociais com base em uma abordagem inatista que desconsidera as condições de vida da população que adoece.

A abordagem crítica e posicionada utilizada na análise dos dados presentes no texto é fundamental em práticas educativas voltadas à transformação social, sejam elas escolares ou não. É a partir dessas problematizações que o ensino e a ciência conseguem se conectar com a realidade de exploração e opressão da maior parte da população e oferecer ferramentas intelectuais que subsidiam o aparecimento do pensamento crítico nas novas gerações.

Os dados relatados e as problematizações realizadas sobre raça, classe e gênero, incitam à reflexão sobre a importância de uma educação anticolonialista/ anticapitalista. Desvelar "What's going on?" na vida real dos sujeitos do processo educativo é parte de uma abordagem educacional revolucionária e não bancária (FREIRE, 2019). Assim, a educação ativista e transformadora supera afirmações naturalistas/inatistas/individualistas acerca do que está acontecendo com os principais atingidos pela Covid-19 (STETSENKO, 2017; STETSENKO; SAWYER, 2020). Se a educação não muda o mundo, ela é um aspecto importante da formação humana, no qual se encontram as intencionalidades capazes de impulsionar nossas ações e ativismos críticos contra o status quo, a colonialidade, o racismo e o machismo. De forma geral, a educação pode servir ao consenso ou ao dissenso, à manutenção ou à transformação. Suas ferramentas intelectuais podem servir para criar seres inteligentes e habilidosos, mas destituídos de um posicionamento crítico sobre o que está acontecendo na vida real, tal como desvelado por este texto. 


\section{I can't breathe: reflexões sobre colonialidade e Covid-19 a partir da cidade de Nova Iorque, EUA}

Conforme Gramsci (1968), a educação não pode ser apenas um meio de instrução técnica e retórica. O educador precisa ser verdadeiro e, num clima de liberdade, superar a mera instrução desenvolvendo o caráter dos estudantes na luta contra a injustiça social. Na opinião do autor, educadores medíocres podem conseguir que estudantes se tornem mais instruídos, mas não serão verdadeiramente cultos e críticos. A escola e a educação precisam ser ligadas à vida e compor uma verdadeira arma da crítica (MARX, 2013).

Assim, este texto, elaborado a partir de dados sobre a manifestação da Covid-19 em Nova Iorque, epicentro da pandemia nos Estados Unidos da América, durante o primeiro semestre de 2020, revela a forma desigual com que ela atinge pobres, negros(as) e migrantes, evidenciando a existência de um 'muro' colonialista separando o Sul dentro do Norte Global. Há um Sul não branco e oprimido que tenta respirar dentro do Norte Global, evidenciando que as últimas palavras de Floyd que inspiraram nosso título, canalizam milhares de vozes negras e latinas, tal qual expressam os dados e as reflexões ao longo deste texto. As mulheres também são fortemente afetadas pelo histórico papel de cuidadoras a elas atribuído e pela violência doméstica à que estão submetidas durante o confinamento com companheiros violentos.

\section{Referências}

ALLEN, Garland E. Essays on science and society: Is a new eugenics afoot? Science, v. 294, n. 5540, p. 59- 61, oct. 2001. Disponível em: https://bit.ly/3o1TpEu. Acesso em: 20 ago. 2020.

BORGES, Beatriz; LARA, Walace. Violência física e sexual contra as mulheres aumenta durante o isolamento social provocado pelo coronavírus. G1, [S. l.], 13 abr. 2020. Disponível em: https://glo.bo/316WO3i. Acesso em: 20 abr. 2020.

CASSIANI, Suzani; LINSINGEN, Irlan von. Resistir, (Re) Existir e (Re)inventar a Educação Científica e Tecnológica. Florianópolis: UFSC, 2019. Disponível em: https://bit.ly/316NlZx. Acesso em: 20 set. 2020.

CASTRO-GÓMEZ, Santigo; GROSFOGEL, Ramón. El giro decolonial: reflexiones para una diversidad epistémica más allá del capitalismo Global. Bogotá: Panamericana Formas e Impresos, 2007.

CONDE, Soraya Franzoni. As condições de trabalho de professores de educação infantil em Santa Catarina, Brasil. Revista Nuances, Presidente Prudente, v. 29, n. 3, p. 165-167, 2018. Disponível em: https://bit.ly/39fekQw. Acesso em: 20 ago. 2020.

DAVIS, Angela. Women, race and class. Los Angeles: Los Angeles book review, 1983. FEDERICI, Silvia. Calibã and witch: women, body and primitive accumulation. New York City: Autonomedia, 2014. 


\section{I can't breathe: reflexões sobre colonialidade e Covid-19 a partir da cidade de Nova Iorque, EUA}

FREIRE, Paulo. Pedagogia do oprimido. São Paulo: Paz e Terra, 2019.

GASPER, Phil. The return of scientific racism. ISR, [S. l.], Issue \#110: Critical Thinking, 2 may 2019. Disponível em: https://bit.ly/39fC9Ys. Acesso em: 20 set. 2020.

GONZALEZ, Lélia. Primavera para as Rosas Negras: Lélia Gonzalez em primeira pessoa. Organizado e editado pela União Coletiva Pan-Africanista. São Paulo: Diáspora Africana, 2018.

GRAMSCI, A. Os intelectuais e a organização da cultura. Rio de Janeiro: Ed. Civilização Brasileira. 2004.

HARVEY, David. Anti-Capitalist Politics in the Time of $=6$-19. David Harvey, [S. l.], 19 mar. 2020. Disponível em:https://bit.ly/2KAFQO0. Acesso em: 27 abr. 2020.

HIRATTA, Helena. Paradigmes du travail: um "point de vue transversal". Paradigmes Du Travail. Futur., Paris, no 16, 1993. Disponível em: https://bit.ly/39kNWVx. Acesso em: 20 ago. 2020.

JIANG, Manyu. The reason Zoom calls drain your energy. BBC News, London, 22 apr. 2020. Disponível em: https://bbc.in/37gRTbc. Acesso em: 24 abr. 2020.

JORDAN, Miriam. Farmworkers, mostly undocumented, become 'essential' during pandemic. New York Times, New York, 2 apr. 2020. Disponível em: https://nyti.ms/366Dhvy. Acesso em: 2 abr. 2020.

LORDE, Audre. Age, race, class, and sex: women redefining difference. Sister Outsider, Trumansburg, NY, p. 114-123, 1984. Disponível em: https://bit.ly/3m8jUHW. Acesso em: 20 set. 2020.

MANACORDA, Mario Alighiero. História da Educação: da antiguidade aos nossos dias. São Paulo: Cortez, 2006.

MARX, Karl. O capital: crítica da economia política. Livro I: O processo de produção do capital. São Paulo, Boitempo, 2013.

MBEMBE, Achille. Necropolítica. 3. ed. São Paulo: n-1 edições, 2018. 80 p.

MESZÁROS, István. A educação para além do capital. São Paulo: Boitempo, 2008.

MIGNOLO, Walter D. Epistemic disobedience, independent thought and decolonial freedom. Theory, Culture \& Society, [S. l.], v. 26, n. 7-8, p. 159-181, 2009.

MLAMBO-NGCUKA, Phumzile. Violência contra as mulheres e meninas é pandemia das sombras, afirma diretora executiva da ONU Mulheres. ONU Mulheres Brasil, [S. l.], 7 abr. 2020. Disponível em: https://bit.ly/2HHZlDm. Acesso em: 24 abr. 2020.

NASCIMENTO, Abdias. O genocídio do negro brasileiro: processo de um racismo mascarado. São Paulo: Paz e Terra, 1978.

NEW YORK (município). NYC Health. COVID-19: Data. New York, 2020. Banco de dados sobre a pandemia de Covid-19. Disponível em: https://bit.ly/2Jf9xn8. Acesso em: 20 set. 2020.

RIET- ISSN 2676-0355, Dourados, v. 2, n. 2, p. 286 a 303, jan./jun., 2021 


\section{I can't breathe: reflexões sobre colonialidade e Covid-19 a partir da cidade de Nova Iorque, EUA}

NOVA Iorque. In: WIKIPÉDIA: a enciclopédia livre. [S. l.: s. n.], 2010. Disponível em: https://bit.ly/3q0ECMp. Acesso em: 20 mar. 2020.

QUIJANO, Anibal. Em torno a la colonialidade del poder. Buenos Aires: Edições del Signo, 2019.

SAFFIOTI, Heleieth. A mulher na sociedade de classes: mito e realidade. São Paulo: Expressão Popular, 2013.

SANTOS, Milton. O espaço do cidadão. 2. ed. São Paulo: Nobel, 1993.

SHIELDS, Stephanie A.; BHATIA, Sunil. Darwin on race, gender, and culture. American Psychologist, [S. l.], v. 64, n. 2, Special issue: Charles Darwin and Psychology, p. 111-119, 2009. Disponível em: https://bit.ly/3fAR9Bp. Acesso em: 20 set. 2020.

SILVEIRA, Daniel. Coronavírus e desafios a prevenção: Brasil tem 31,3 milhões sem água encanada e 11,6 milhões em casas superlotadas. G1, Rio de Janeiro, 28 mar. 2020. Disponível em: https://glo.bo/366HaR0. Acesso em: 20 set. 2020.

STETSENKO, Anna. The transformative mind: Expanding Vygotsky approach to development and education. Cambridge: Cambridge University Press, 2017.

STETSENKO, Anna; SAWYER, Jeremy. Culture and Development. SAGE Publications, Thousand Oaks, v. 2, p. 211-213, 2016. Disponível em: https://bit.ly/37agZIC. Acesso em: 20 set. 2020.

TAYLOR, Keeanga-Yamahtta. Raça, classe e marxismo. Tradução: Maíra Mee. Revista Outubro, Rio de Janeiro, n. 31, $2^{\circ}$ sem. 2018. Não paginado. Disponível em: https://bit.ly/2KAf4oW. Acesso em: 20 set. 2020.

VENDRAMINI, Célia; CONDE, Soraya Franzoni. Vítimas do Coronavírus: a classe trabalhadora migrante. Portal Desacato, [S. l.], 30 abr. 2020. Disponível em: https://bit.ly/39eW9dL. Acesso em: 5 maio 2020.

WALLACE, Robert G. Big farms make big flu: dispatches on infectious disease, agribusiness, and the nature of science. New York: Monthly Review Press, 2016.

WILHIANS, J. Letter to Major Bill de Blasio. Inquiry regarding disparities in COVID-19 testing. April/2nd/2020.

WORLD HEALTH ORGANIZATION. Corona Virus Disease. Weekly Epidemiological Update and Weekly Operational Update. WHO, [S. l.], 2020. Disponível em: https://bit.ly/3aKYj5E. Acesso em: 5 jun. 2020.

YANCY, George. Through the crucible of pain and suffering: African-American philosophy as a gift and the countering of the western philosophical metanarrative. Educational Philosophy and Theory, [S. l.], v. 47, n. 11, p. 1143-1159, 2015. Disponível em: https://bit.ly/3q3NErX. Acesso em: 20 set. 2020.

RIET- ISSN 2676-0355, Dourados, v. 2, n. 2, p. 286 a 303, jan./jun., 2021 